\title{
Peer Tutoring on Facebook to Engage Students with Flipped Classes: A Correlational Experiment on Learning Outcomes
}

\author{
Full Paper \\ Amir Talaei-Khoei \\ University of Technology Sydney \\ amir.talaei@uts.edu.au \\ Jay Daniel \\ University of Technology Sydney \\ jay.daniel@uts.edu.au
}

\begin{abstract}
This paper aims to demonstrate the potentials of using Facebook to improve the students' engagements with the flipped learning materials through implementation of socially enabled peer learning. The article looks at comparing the correlations between the learning outcomes with online quizzes as well as with the Facebook engagement of students. The findings show that although the learning outcomes are correlated with the both of these two interventions, the students' engagement on Facebook has a stronger correlation with the learning outcomes in the flipped classes. The study also reports the lessons learned in deploying Facebook groups to implement peer learning in flipped classes. The results have been discussed in the lens of Theory of Peer Learning and the future avenues of research have been suggested. This study also motivates teaching practitioners in Information Systems to improve flipped learning by the use of social networking sites in their courses.
\end{abstract}

\section{Keywords}

Social networking sites, flipped learning, peer tutoring.

\section{Introduction}

In recent years, implementation of flipped learning strategies has become more prevalent. Missildine et al (2013) defines flipped learning as a hybrid method that uses interventions to interchange lecture time to "homework" and utilizes interactive learning for the face-to-face lecturing time. Flipped classes encourage students to learn the contents of the course in advance to come to class and practice the materials with discussion or task-oriented exercises ( $\mathrm{Li}$, Lou, Tseng, \& Huang, 2013). There has been a body of literature that reveals various advantages of flipped classrooms. However, some challenges have also been reported in their implementation of flipped classes.

Elliott (2014) introduces "front loading" challenge for the implementation of flipped classes. Flipped Learning requires a strong motivation enabling students to prepare the work in advance as compared to lectures. In fact, due to more work preparation required for Flipped Learning, a survey done in a study by DeSantis, Van Curen, Putsch, \& Metzger (2015) reveals that students are less satisfied with Flipped Learning versus traditional learning. This basically leads to less students' engagement with the materials. Missildine et al. (2013) believes the demotivation among students to engage with the flipped class materials is due to the lack of social context in learning the contents before coming to the lectures. Topping (2005) believes that peer support can occur through tutoring process or a goal-oriented collaborative learning in a group. Peer tutoring looks at the interactions among students with the focus on the curriculum. While the peer tutoring has been shown in literature as an effective practice for improving students' engagement (Ashwin, 2003; Kuh, 2009), Bishop \& Verleger (2013) implement an online discussion forum and highlight the role of collaborative tools to facilitate the peer tutoring and engaging students with flipped learning materials. 
The role of social networking sites (SNS) such as Facebook in facilitating peer learning practices to improve the students learning has been highlighted in the literature (Talaei Khoei \& Talaei-Khoei, 2015). While Li et al. (2013) indicate that students' engagement with flipped materials using Facebook is higher compared to traditional learning, the relationship between using social networking sites like Facebook for flipped classes and the students' learning outcomes has not been addressed. There are two main reasons for the choice of Facebook over other alternatives. First, Facebook has been proven as a successful platform in terms of user engagement (Heiberger \& Harper, 2008). Second, students prefer Facebook for both socialize and facilitating peer learning. In a large-scale study (Kumpikaite, Duoba, \& Taraskevicius, 2011), 91\% of undergraduate students claimed that they hold and use a Facebook account. Among these, $54 \%$ of students utilize Facebook for their learning. Grosseck et al. (2011) state that students prefer Facebook over discussion boards in the learning management systems because of the rigid structure of the discussion boards and also social connections that Facebook provides.

This paper looks at the correlation of discussions on Facebook about the topic of the lecture before joining to the class and the learning outcomes of students. It is believed that Facebook facilitating peer tutoring and providing social context to the flipped learning can improve students' engagement prior to the class with the materials and accordingly improves the learning outcomes. The paper is an attempt to address the following research question:

- How do the correlation of practicing the flipped materials on the Facebook and on the online learning management system with the students' learning outcomes compare?

The article reports an experiment in a second-year undergraduate course in Information Systems major, in which the students were asked to participate in four flipped learning classes. Prior to these classes, the students were given content materials as well as discussion questions. In two of these classes the discussion questions were provided on the online learning management system as individual voluntary quizzes. However, in the other two classes the discussion questions were provided on the Facebook group of the class. The correlations of students' engagement and their learning outcomes were compared in these two interventions. It was revealed that in both cases, the correlation between either the students' engagement on the online quizzes or their Facebook engagement with their learning outcomes were high. However, comparing these two relationships, the correlation between the Facebook engagements with the learning outcomes was stronger.

The rest of this paper is organized in the following way. The section for methods presents the way that the data was collected and analyzed. The readers can also find more details about the course. The section for results presents what has been found in the analysis. Finally the last section discusses the findings and suggests future works. This section also presents the limitations of this study.

\section{Method}

\section{Context}

The students in a second-year undergraduate course in Bachelor of Information Systems were invited to participate in the study. Only 11 students did not participate, which remained the experiment with 284 students (range $19-37$ years; Mean $=22.1 ; \mathrm{SD}=2.3 ; 154$ males).

The topic of the course was enterprise resource planning (ERP) from management perspective, but with some technical flavor such as introducing the technologies that can be used in ERPs. The course did not involve any hands on experience by students but focused more on managing an ERP system in an organization. For twelve weeks, the course had one and half hours of lectures and one and half hours of tutorial/workshop sessions weekly. The lectures were given by the course coordinator and the tutorials in classes of 24 students were managed by teacher assistants.

\section{Design}

The course offered four flipped classes; two at the earlier stage of the semester and two at the later stage. In all these four classes, the lecture materials were provided to students on the online management systems to study prior to the class. Some extra videos were also provided. In the first flipped class in week 3 and the fourth flipped class in week 10 the students were asked to participate in an online voluntary quiz 
that included five discussion questions about the topic. In the second flipped class in week 5 and the third experiment in week 8 , students were asked to voluntary discuss five discussion questions on the Facebook group of the course. Then, in all these four flipped classes in weeks 3, 5, 8 and 10, the students when physically participating in the class were given five similar but not the same questions about the topic of the week in hardcopy. Their performance was recorded.

\section{Analysis}

The quantitative analysis phase in this experiment was involved the study of correlations among three different constructs; namely (1) students' engagement in the online quizzes prior to the class, (2) students' engagement in the Facebook group discussions before the class and (3) students' learning outcomes. For this to happen, we took the following three steps:

- Step 1 - Measurement: The following three measures were defined for each of the abovementioned constructs and calculated for each participant:

- Engagement with the Flipped Online Quizzes: the students on the first and fourth experiments were given five online discussion questions that each could be graded to the maximum of one mark (five marks in total). These marks were given by the teacher and based on the answers entered.

- Facebook Engagement: Instead of online quizzes, in the second and the third experiments, the students were asked to discuss five discussion questions on the Facebook group of the course. The students' engagement on the Facebook group of the course in a particular experiment on week 5 or 8 was calculated by average number of the student's post for each question. This was measured for each student in the second and the third experiments separately.

- Learning Outcome: The students' learning outcome was calculated by their answers to the five discussion questions given to them in the class in all four experiments.

- Step 2 - Calculating the Correlation Efficient: In each experiment, the correlation between the data sets of the students' Engagement with either the Flipped Online Quizzes or Facebook discussions and the Learning Outcome was calculated. In order to do so, the Bivariate Correlation Analysis was conducted in SPSS to calculate correlation coefficients $(r)$. The significant level of these correlations was measured by $p$-value. One may say that the correlations between students' Engagement with the Flipped Online Quizzes or Facebook discussions and Learning Outcome are because of the natural correlation between Flipped Online Quizzes and Facebook discussions. For example, a possibility is that one may participate in Facebook just because he/she was very active and as such she/he became interested in the topic. However, this cannot be the case, as these experiments were conducted separately and on different weeks.

- Step 3-Comparing the Correlations: In this step, the calculated correlation in the first and the second experiments as well as the third and the fourth ones would be compared. It would help us to see our comparison provides us similar results at the beginning and at the end of the semester. Using the Fisher $r$-to-z transformation (Weaver \& Wuensch, 2013), we calculate a value of $z$ that can be applied to assess the significance of the difference between two correlation coefficients, found in two independent samples of the correlations between the students' Engagement in Online Flipped Quizzes and their engagement on Facebook with the learning outcomes. We repeat the comparison for comparing samples of the first experiment with the second experiment as well as the third experiment with the fourth one. The comparison of correlations can only meaningful if they are significantly different.

Having done the above three steps, the null hypothesis explaining the significance of the difference between the correlation of the students' Engagement in the flipped online quizzes with the learning outcome and Facebook Engagement with the learning outcomes would be retained or rejected. The results can be double checked across the beginning and the end of the semester. The correlations in all above calculations were considered as 2-tailed. 
In order to analyze the qualitative notes, the teaching team including the lecturer and the teaching assistants were meeting after each flipped learning week and discussed their observations. At the end of the semester, the notes and the observation findings were concluded in a workshop of 12 academics who were involved in teaching similar courses.

\section{Results}

\section{Quantitative Results}

Comparison of the First and Second experiments: Following the guidelines of Evans (1996), the results indicated that the correlation between the students' engagement in the flipped quizzes and their learning outcome in the first experiment was high but not significantly high $(r=0.697, p<0.001)$. However, it was found that the correlation between the students' engagement with Facebook group discussions and their learning outcomes was significantly high in the second experiment $(r=0.728, p<0.001)$. The Evans (1996) guidelines indicated the the correlation between the students' engagement with the flipped quizzes and their Facebook Engagement was weak $(r=0.121, p<0.001)$.

The difference between these correlations was highly significant, $z=3.171, p<0.018$. Therefore the Null Hypothesis implying the no significant difference between these two correlations was rejected. It was revealed that the correlation between the students' Facebook engagements with their learning outcomes was significantly stronger than the correlation between their engagement in the flipped quizzes and their learning outcome. One may say this can be influenced by the correlation between the students' engagement on Facebook with their engagement in the flipped quizzes. However, this correlation has been found not significant.

Comparison of the Third and Fourth experiments: The results found in the beginning of the semester were confirmed by the comparison of the correlations at the end of the semester. It was found that the correlation between the students' engagement in the flipped quizzes and their learning outcome in the fourth experiment was high but not significantly high $(r=0.649, p<0.001)$. However, it was found that the correlation between the students' engagement with Facebook group discussions and their learning outcomes was significantly high in the third experiment $(r=0.801, p<0.001)$. The Evans (1996) guidelines indicated the the correlation between the students' engagement with the flipped quizzes and their Facebook Engagement was weak $(r=0.128, p<0.001)$.

The difference between these correlations was highly significant, $z=4.171, p<0.026$. Therefore the rejection of Null Hypothesis implying the no significant difference between these two correlations was confirmed. The result of the comparison of the first and the second experiment was acknowledged by comparing the third and the fourth experiments. The correlation between the students' engagement on Facebook with their engagement in the flipped quizzes was found insignificant.

All in all, it was found that the correlation between the students' Facebook engagements with their learning outcomes was significantly stronger than the correlation between their engagement in flipped quizzes and their learning outcome in the course.

\section{Qualitative Observational Results: Lessons learned to improve students' engagement with Flipped Learning Materials using Facebook}

The qualitative findings have been extracted from several informal discussions between the course coordinator/lecturer and the students as well as the direct observations of the teaching team. These findings were discussed first among the teaching team in the meetings after each flipped class and then concluded in a workshop of 12 academics teaching similar courses.

\section{Facebook increases students' motivation to engage with the flipped learning materials prior to the class.}

It was found that the students could get more motivated by Facebook to the flipped learning classes and studied the materials prior to the class when using Facebook as an online collaborative tool. The students were very excited to see others' opinion and carry the discussions. This could get them engaged with the materials. It was said by a student in an informal chat, that the discussions on the Facebook motivates 
him to go and learn the topics. This self-learning component that was motivated by the discussions on Facebook is the main objective of the flipped learning practices. While the students' engagement to the self-learning of materials has been reported as a problematic issue in Flipped classes by Elliott (2014) as well as DeSantis, Van Curen, Putsch, \& Metzger (2015), Facebook seem to be effective to engage students.

\section{Facebook cultivates a collaborative environment and improves learning.}

It was observed that the students were enjoying the discussions on the Facebook and they believed that discussions from peers significantly contribute in their learning experience. From what it was seen by the teaching team, students thought Facebook in comparison to online quizzes provided a collaborative environment that improves their learning. It was interesting to see that students enjoyed feedbacks from their peers for their initial thoughts on Facebook. It was seen that the answers to the questions were getting mature over a discussion among students. The students believed that learning from different perspectives was very useful to improve their learning experience.

\section{Sense of community encourages students to engage with the flipped materials.}

A sense of community to the group when students used Facebook to discuss the flipped materials was identified. The students could spend a great deal of time paying attention to other members to make sure that they have understood the flipped materials. In some occasions, it was observed that the students also search online to seek extra materials and even put it up as a link to others in the Facebook group. This is consistent with the finding of (Abedin, Daneshgar, \& D'Ambra, 2010) about sense of community in online learning. It also acknowledges the findings of (Talaei Khoei \& Talaei-Khoei, 2015) for the use of Facebook to encourage peer tutoring but in the current study it is for implementation of flipped learning.

\section{Privacy concerns that students express to use Facebook can settle when students exprience the intervention.}

It was found that few students expressed some concerns about their privacy when using Facebook. Although the students were given an option to use a Facebook account that is only being used for the intervention, there was no student that actually used such an account. The same students also were asked after the second flipped class if they are still concerned, none showed any. It was interesting to see once students actually start to use the Facebook groups, they see that this is not about getting into their private and personal life but it is about them getting encouraged to engage with the materials. Their experience helped them to feel more comfortable with the intervention and the new model of learning.

\section{Advantages, disadvantages and recommendations for the use of Facebook as an online collaborative tool for flipped learning}

Overall, the students informally expressed their general satisfaction with the use of Facebook. They believe Facebook provides ease of use and ubiquitous access. They think it is much easier to see the posts on their Facebook provided its anytime and anywhere feature, compared to logging into the online management system. Facebook provides more user friendly environment that is also mobile adaptable. The students pointed out that Facebook supports the interactive communication and collaboration among the peers. The advantage of Facebook in comparison of other social media that are specifically designed for education is that learners are very much familiar with the use, and this motivates them to adopt it as they no longer need to learn the system. This is consistent with the results of Li et al. (2013).

However, students think that the large number of notifications on Facebook can be disturbing. They found that they can actually change the setting to solve the issue. They also believe Facebook has some technical limitations. For example, the students who do not catch with a discussion because it will be sorted by time, then finding a discussion would be very difficult. Similarly, if a student posts on a discussion few weeks later, the discussion will come up as the current discussion. However, the coordinators are suggested to pin the current discussion to solve the issue. In addition, sometime Facebook lacks some of the symbols that are being used in more technical discussions.

The students recommended that the use of polls in Facebook can improve the engagement. They have also recommended that when the coordinator provides a discussion post, he enables the reply option for each 
answer. Then, the students can reply directly to that particular comment than providing their answer as a comment.

\section{Conclusion, Discussion and Future Work}

In this paper, an experiment has been reported on 284 second year Information System students for an ERP undergraduate course. The experiment was a longitudinal correlational study in four flipped classes on weeks $3,5,8$ and 10 . In these four classes, the students were given the materials prior to the class on the learning management system. While the first and the last class required students to participate in online quizzes including five discussion questions in advance to the physical presence in the class, the second and the third classes needed the students to participate in the five discussion posts put by the course coordinator on the Facebook group.

It was revealed that in both cases, the correlation between either the students' engagement on the online quizzes or their Facebook engagement with their learning outcomes were high. However, comparing these two relationships, the correlation between the Facebook engagements with the learning outcomes was stronger.

There has been a body of literature in the support of collaborative tools to improve the students' engagement with the flipped class materials (Bishop \& Verleger, 2013). Although discussion boards in the online learning management systems are powerful tools to handle content-related collaborative interactions, they lack a comprehensive social engagement and non-pedagogical relationships among students that required for an effective peer tutoring environment (Hrastinski, 2008). Social engagement among learners can be boosted by social media sites such as Facebook (Abedin, 2011). Li et al. (2013) studied the acceptance of Facebook to provide social context in the online flipped materials and believe due to the fact that the students are already familiar with Facebook, they would engage with this platform easier than other available alternatives.

Although the current study does not look at the casual relationships between these constructs and only investigated the correlations, it suggests the potentials for such learning practices on Facebook as a new delivery model to improve students' engagement and learning outcomes by implementing online peer tutoring in flipped classes.

\section{Theory of Peer Learning: Justifications and Avenues of Research for Quantitative Results}

Topping (2001) define the peer learning constructs as the interaction of five constructs; namely organizational or structural features, cognitive conflicts, error management, communication and affective components. In this section, the applications of these constructs in flipped classes on Facebook are going to be discussed.

One of the main organizational advantages of using Facebook group comparing to the online quizzes to implement flipped learning is the power of crowd and the social context that this setting creates. This concept is built on the social notation that the engaging students with the learning materials before the flipped class does not occur only because of the quality of materials but also with a social context with variety of people. Although the students in all the flipped classes were given access to the discussion questions, their contributions on the quizzes were not correlated with their learning outcomes as strongly as their engagement with the Facebook discussions. This potential is in stark contrast with the concept of individualization of learning in smallgroups introduced in the Topping's model of peer learning (K. J. E., Stewart W. Topping, 2001). Therefore further research in this area is required to investigate the actual individualization of learning that occurs during crowd communications over Facebook in comparison of downsizing it to a small group in the context of flipped learning. Although the current study demonstrates the stronger correlation of learning outcomes with the engagement on the Facebook group of the course comparing to individual quizzes, the Topping's claim on the contribution of small groups needs further doubtful investigations. This is also in support to the recent work of (Talaei Khoei \& Talaei-Khoei, 2015) marrying the theory of social learning (Parke, 2014) and peer learning (K. J. E., Stewart W. Topping, 2001). 
Cognitively, peer learning requires challenging as well as supporting the learners' opinions. Facebook providing the immediacy and crowd in feedbacks can empower the peer tutoring required to engage students with the flipped materials. Bishop \& Verleger (2013) believe that the implementation of peer tutoring can improve the students' engagements with the flipped materials.

Error management is a monitoring mechanism that has been introduce in peer learning model of Topping (2001). In some informal conversations, students expressed their worry that in flipped classes there is a risk of misunderstanding the materials. However, they were very impressed with the fact that on Facebook people talk and discuss about some aspects of the course that they could not realize it themselves. Therefore, these points came to their attention without even asking them or thinking about them.

One of the drawbacks for the flipped learning is an assumption of the same comprehension from the written and visual communication materials given to the students prior to the class. This is clearly an optimization. Beside the variety and the differences of communication skills among students, not to say that we also have international students that may require extended time in understanding written and visual materials. This would be hard in the context of flipped learning when the comprehension is only relying on a one-way written or visual channel. The Facebook group gives all students this opportunity to relax from the pressures of the one-way communication channels. However, this needs further investigation by empirical results from the students' perspective.

From affective components there are few considerations that are required to be taken into account. For example in practicing flipped learning on Facebook comparing to the online quizzes, Lockyer and Patterson (2008) believe that learning in such informal settings as Facebook is not considered a highly conscious activity. However, the results of this work are in stark contrast with the Lockyer and Patterson's statement (2008). The sense of community has also been shown as a very effective element in improving learning outcomes in social networking sites such as Facebook (Abedin et al., 2010).

\section{Insights from Qualitative Results}

Most students believe that Facebook enables a collaborative environment in flipped learning as it stimulates online discussion among students wherein they learn from different perspectives. They also feel that Facebook provides convenience of use as it is flexible to use from anywhere and at any time. Moreover, given that they are familiar with Facebook's user interface then using it in flipped learning is not difficult. For students, it is an interactive and engaging tool; it stimulates self-learning and improves their understanding of the subject. Facebook also enables information to be easily accessible and available to the students.

Despite the positive features, the students experienced some of issues and limitations in using Facebook for their Flipped Learning activities. Mainly, they feel that Facebook only supports for limited discussions thus there were repetitive answers to questions. Hence, they felt that there was a need for more openended questions. The platform also caused some issues such as the number of notifications and spamming that the students received. There were also concerns on the limitation of what you can do in Facebook. Some students also raised that they do not regularly use Facebook and some found going to the social media site brought a distracting aspect to learning. It was notable though that on the second round of the Flipped Learning activity, there were no statements on issues for the privacy concerns. This shows once the students became comfortable with the intervention, they realized that the Facebook group of the slipped learning class is not to intervene with their privacy, but to provide an effective channel of discussion for flipped materials.

It also appears that conventional online learning environments such as Blackboard and Moodle have definite limitations when compared to Facebook. The push mechanisms of Facebook that indicate a new discussion point to students on their smart phone means that the University course they are undertaking can be more actively at the forefront of their daily life, which itself increases their engagement with the materials. This constant reminder of discussion points can help students become more involved with their studies. The down side of this is the 24/7 engagement with technology that is occurring not only for students but many people (in particular employees) at all levels of human endeavor. 


\section{Comparison of the Current Work with Related Studies}

Li et al. (2013) has addressed the acceptance of Facebook by students to engage them with the flipped materials. The work indicates that because the students are already familiar with Facebook, they do not need to go through a complete learning curve when deploying Facebook to engage them with flipped materials prior to the class. However, the direct correlation between the use of Facebook for this matter and the students' learning outcomes was ignored. The current work demonstrates the potentials of Facebook as an online collaborative tool to improve students' engagement with the flipped materials and accordingly their learning through a socially enabled online peer tutoring practice.

Talaei Khoei \& Talaei-Khoei (2015) has conducted a similar correlational experiment and demonstrated that the use of Facebook can effectively improves the peer tutoring practice in the class and as a result the students' learning outcomes can be improved. However, the study did not look at the applications of the results into flipped classes. The current paper, instead, conducted an experiment that included flipped learning practice. While our results are consistent with the correlational experiment presented by Talaei Khoei \& Talaei-Khoei (2015), the current study only demonstrates the applications of Facebook in improving learning outcomes for flipped class.

\section{Limitations}

The present work examined the relationship of the students' engagement in online quizzes and Facebookbased discussions with their learning outcomes in flipped classes. The statistical procedure - correlation used in this work does not evaluate possible casual relationships between these constructs. Therefore, due to the different objective of this work, it cannot be concluded that deploying the Facebook groups are more effective flipped learning practice comparing to online quizzes. However, it opens an opportunity for future studies to investigate the causalities among these constructs.

The major limitation of observations in this study is the social complexity involved in the experiments. This makes it almost impossible to conduct complete cross analysis.

A further limitation related to this study is that the experiments did not allow finely tuned analysis of individual differences in the outcomes of the study. Nakayama et al. (2015) believe that one consideration in the use of social media for flipped learning is that the personality differences of students impact their frequency of use of Social Network Sites. Thus, it introduces a new variable that affects the flipped learning strategy and this has not been taken into the scope of the current work. Given the importance of individual differences on outcomes, further research should examine the relationship between antecedents such as gender, parental education level, etc. on student engagement with the flipped learning materials. This can serve as a future study.

\section{REFERENCES}

Abedin, B. (2011). Web 2.0 and online learning and teaching: A preliminary benchmarking study. Asian Social Science, 7(11), p5.

Abedin, B., Daneshgar, F., \& D'Ambra, J. (2010). Underlying factors of sense of community in asynchronous computer supported collaborative learning environments. Journal of Online Learning and Teaching, 6(3), 585-596.

Ashwin, P. (2003). Peer support: Relations between the context, process and outcomes for the students who are supported. Instructional Science, 31(3), 159-173.

Bishop, J. L., \& Verleger, M. A. (2013). The flipped classroom: A survey of the research. In ASEE National Conference Proceedings, Atlanta, GA.

DeSantis, J., Van Curen, R., Putsch, J., \& Metzger, J. (2015). Do Students Learn More From a Flip? An Exploration of the Efficacy of Flipped and Traditional Lessons. Journal of Interactive Learning Research, 26(1), 39-63. 
Elliott, R. (2014). Do students like the flipped classroom? An investigation of student reaction to a flipped undergraduate IT course. In Frontiers in Education Conference (FIE), 2014 IEEE (pp. 1-7). IEEE.

Evans, J. D. (1996). Straightforward statistics for the behavioral sciences. Brooks/Cole.

Hrastinski, S. (2008). Asynchronous and synchronous e-learning. Educause Quarterly, 31(4), 51-55.

Kuh, G. D. (2009). What student affairs professionals need to know about student engagement. Journal of College Student Development, 5o(6), 683-706.

Li, K.-H., Lou, S.-J., Tseng, K.-H., \& Huang, H.-C. (2013). A preliminary study on the Facebook-based learning platform integrated with blended learning model and flip learning for online and classroom learning. In Advances in Web-Based Learning-ICWL 2013 (pp. 172-183). Springer.

Lockyer, L., \& Patterson, J. (2008). Integrating social networking technologies in education: a case study of a formal learning environment. In Advanced Learning Technologies, 2008. ICALT'08. Eighth IEEE International Conference on (pp. 529-533). IEEE.

Missildine, K., Fountain, R., Summers, L., \& Gosselin, K. (2013). Flipping the classroom to improve student performance and satisfaction. Journal of Nursing Education.

Nakayama, M., Leh, A., \& Santiago, R. (2015). Relationships of Student Experience and Student Characteristics in a Graduate-Level Flipped Classroom. In Proceedings of the 2nd European Conference on Social Media 2015: ECSM 2015 (p. 348). Academic Conferences Limited.

Parke, R. D. (2014). Recent trends in social learning theory. Academic Press.

Talaei Khoei, T., \& Talaei-Khoei, A. (2015). Peer Learning in the Class or on Facebook? A Correlational Experiment on Learning Outcomes. AMCIS 2015 Proceedings. Retrieved from http://aisel.aisnet.org/amcis2015/ISEdu/GeneralPresentations/7

Topping, K. J. (2005). Trends in Peer Learning. Educational Psychology, 25(6), 631-645. http://doi.org/10.1080/01443410500345172

Topping, K. J. E., Stewart W. (2001). Peer Assisted Learning: A Framework for Consultation. Journal of Educational \& Psychological Consultation, 12(2), 113-132.

Weaver, B., \& Wuensch, K. L. (2013). SPSS and SAS programs for comparing Pearson correlations and OLS regression coefficients. Behavior Research Methods, 45(3), 880-895. 